\title{
Research on flow boiling heat transfer for vertical upward and downward flows along a minichannel with a smooth heated surface
}

\author{
Kinga Strąk $^{1, *}$, and Magdalena Piasecka ${ }^{1}$ \\ ${ }^{1}$ Kielce University of Technology, Faculty of Mechatronics and Mechanical Engineering, al. 1000-lecia P.P. 7, 25-314 Kielce, Poland
}

\begin{abstract}
The paper reports results for flow boiling heat transfer in a $1.7 \mathrm{~mm}$ deep minichannel verticallyoriented with upward and downward flow. The heated element for HFE-649 flowing upward or downward in a channel was a smooth plate. Infrared thermography allowed determining changes in temperature on the outer plate side. Two-phase flow structures were recorded through a glass pane at the other side of the channel being in contact with the fluid. Analysis of the results was performed on the basis of experimental series obtained for the same heat flux for upward and downward flows and two mass flow velocities. The results are presented as relationships between the heat transfer coefficient or the plate temperature and the channel length, boiling curves, and between the heat flux and the heat transfer coefficient and two-phase flow structure images. The impact of mass flow velocity on the heat transfer coefficient and two-phase flow structures for vertical upward and downward flows were discussed.
\end{abstract}

\section{Introduction}

Heat transfer in small channels has been studied intensively over the last few years. The main application of small channels was cooling electronic systems and their components. Mini heat exchangers will reduce their sizes and costs, while the consumed power is identical in comparison to conventional sized heat exchangers. They are used to provide higher cooling capability for new technologies. Owing to the change of the state which accompanies flow boiling in small channels, it is feasible to meet contradictory needs simultaneously, i.e. obtain a heat flux as large as possible at small temperature difference between the heated surface and the saturated liquid while retaining small dimensions of heat transfer systems.

Extensive studies are conducted to understand the phenomena with change of phase (boiling or condensation during flow in minichannels [1-22]: and 'pool boiling' [23-26]). Research reported in the literature finds that different orientation of test sections is an important factor in flow boiling heat transfer models in mini spaces. In [8], the researchers examine complex trends of flow boiling critical heat flux (CHF) in a rectangular channel at eight angular positions $\left(0^{\circ}, 45^{\circ}, 90^{\circ}, 135^{\circ}, 180^{\circ}, 225^{\circ}, 270^{\circ}, 315^{\circ}\right)$ in both microgravity and Earth gravity. The authors reported that CHF sensitivity to orientation was lower for upflow and upward-facing heated wall positions $\left(0^{\circ}-90^{\circ}\right)$ and higher for downward flow and downward-facing wall positions $\left(180^{\circ}-270^{\circ}\right)$. The CHF mechanism in Earth gravity is shown to be highly sensitive to flow orientation at very low velocities.

In [9], while questioning the effect of gravity on $\mathrm{CHF}$ mechanisms, the authors show that the influence of orientation can be negated when the influence of gravity perpendicular and parallel to heating walls is overcome and when the sufficient length of the heated wall is provided to ensure liquid contact.

In [10], subcooled flow boiling critical heat flux measurements are taken over a range of flow positions: $0^{\circ}, 45^{\circ}, 90^{\circ}, 135^{\circ}, 180^{\circ}, 225^{\circ}, 270^{\circ}$, and $315^{\circ}$ with respect to gravity. The findings exhibit an increase in CHF with increasing velocity and a considerable consolidation of data at different positions at the highest velocity.

The results of the Kielce University of Technology study on flow boiling heat transfer with $\mathrm{FC}-72$ in a minichannel positions: $0^{\circ}, 45^{\circ}, 90^{\circ}, 135^{\circ}$ and $180^{\circ}$ with respect to the horizontal plane are described in [11]. In their previous paper [12], the authors report the results of flow boiling heat transfer experiment with several refrigerants (FC-72, HFE-7100 or HFE-7000) in an asymmetrically heated rectangular minichannel inclined at seven angles $\left(0^{\circ}, 30^{\circ}, 60^{\circ}, 90^{\circ}, 120^{\circ}, 150^{\circ}\right.$, and $\left.180^{\circ}\right)$ relative to the horizontal plane. The highest values of local heat transfer coefficients were observed at the inclination angle of $60^{\circ}$ with HFE- 7000 and at $180^{\circ}$ with FC-72 (the subcooled boiling region) and all minichannel positions with FC-72 (the saturated boiling region).

\footnotetext{
Corresponding author: kzietala@tu.kielce.pl
} 


\section{Experimental stand}

The experimental setup comprises the main loop with refrigerant HFE-649 (3M), the data and image acquisition system, the supply and control system and the lighting system (Fig. 1a).

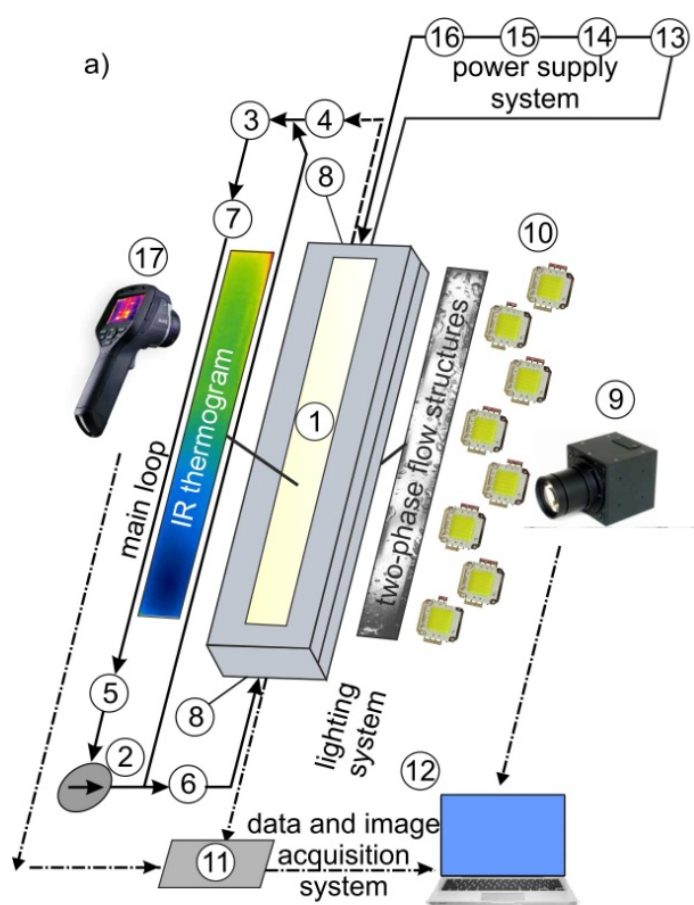

b)

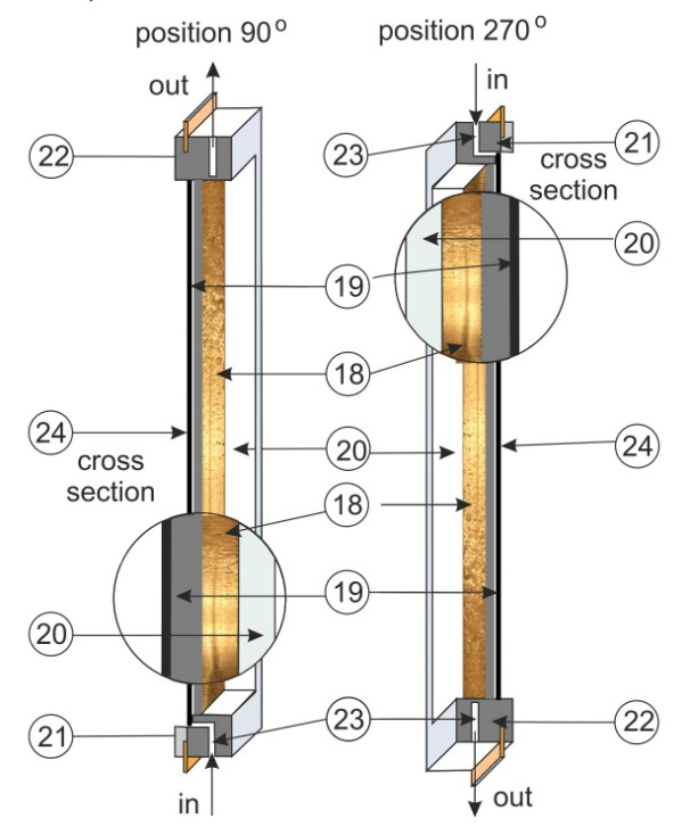

Fig. 1. a) The schematic diagrams of: a) the main systems of the experimental setup, 1-test section with a minichannel; 2-gear pump, 3-compensating tank/pressure regulator, 4-tubetype heat exchanger, 5-filter, 6-mass flowmeter, 7-deaerator, 8-pressure meter, 9-fast camera, 10-high power LEDs (400 W), 11-data acquisition station, 12-pc computer, 13-inverter welder, 14-shunt, 15-ammeter, 16-voltmeter, 17-infrared camera; b) the test section for vertical upward and downward flows along the minichannel: 18-minichannel, 19-heated plate, 20-glass panel, 21-channel body, 22-front cover, 23-thermocouple, 24-black paint layer.
The vertically-oriented rectangular minichannel with the upward flow (denoted as position $90^{\circ}$ ) and the downward flow (denoted as position $\left.270^{\circ}\right)^{\circ}$, was an essential element of the setup (Fig. 1b).

The minichannel had a depth of $1.7 \mathrm{~mm}$, a width of $16 \mathrm{~mm}$ and a length of $180 \mathrm{~mm}$. Its heated wall was a smooth plate of thickness of about $0.45 \mathrm{~mm}$ (7, Fig. 2a). This plate was made of Haynes-230 alloy manufactured by Haynes Int. Inc. (USA). In addition to excellent high-temperature strength and oxidation resistance, the alloys exhibit superior long-term stability, fabricability [27] and has good weldability [28] and allows you to create diffusion joints - possibilities of combining metal sheet with metallic foams using a sintering powder mixture in dissociated ammonia [29].

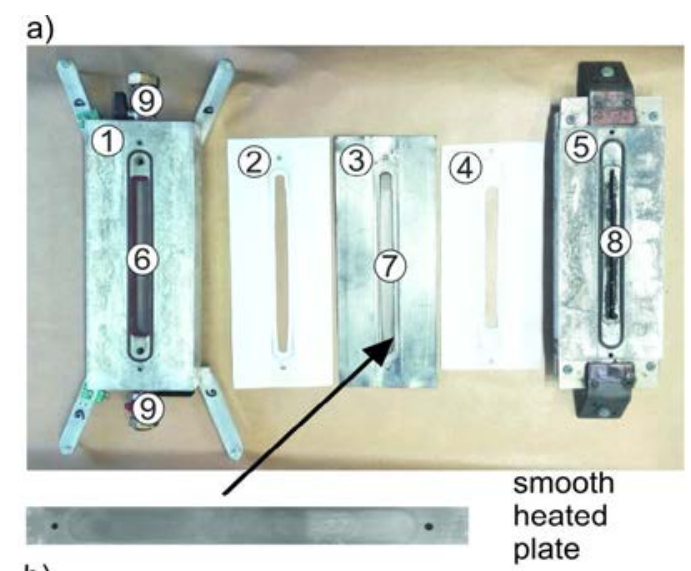

b)
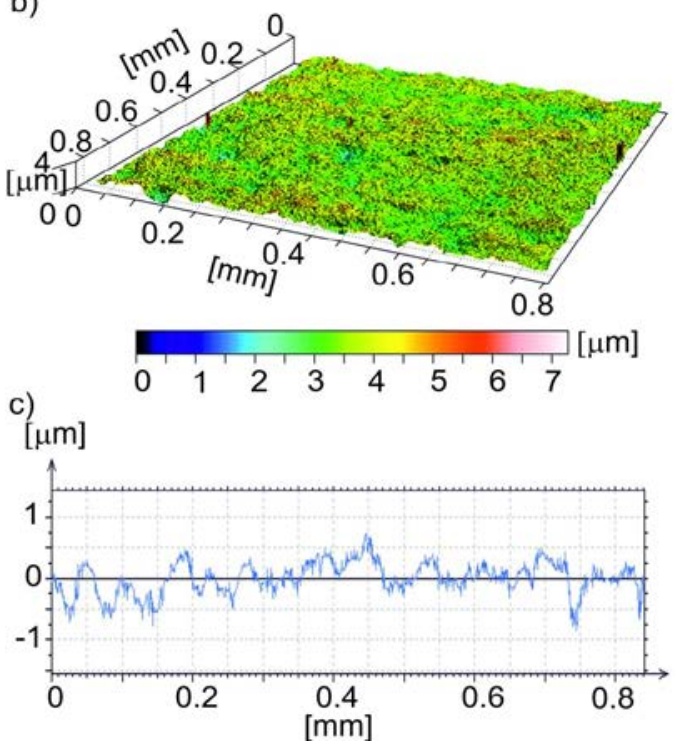

Fig. 2. a) Image of main elements of the test section. 1-front cover, 2,4-teflon plate, 3-graphite plate, 5-channel body, 6-glass panel, 7-heated plate, 8-micanite panels, 9-thermocouple; b,c) analysis of a fragment of the plate's smooth surface: 3D topography (b) and roughness profile (c).

Figures 2b-c show the 3D topography of fragment of the plate's smooth surface (b) and a roughness profile (c). The surface parameters roughness were: arithmetic mean deviation of the roughness profile $R a=0.175 \mu \mathrm{m}$ and arithmetic mean height $S a=0.346 \mu \mathrm{m}$. Image of the test section with the minichannel was shown on Fig. $2 \mathrm{a}$. The channel depth is provided by a Teflon plate of 
adequate thickness (2). The outer smooth side of the heated plate of the minichannel was strengthened on both sides with narrow micanite panels (8) to prevent the plate surface from deforming.

In the experimental series was measure the surface temperature of the outer side of the plate in the central, axially symmetric part of the channel, using a contactless method using an E60 FLIR infrared camera. The accuracy of the infrared camera temperature measurement is $\pm 1{ }^{\circ} \mathrm{C}$ or $\pm 1 \%$ within the temperature range of $0-120{ }^{\circ} \mathrm{C}[13]$. The two-phase flow structures were observed simultaneously through a glass panel at the other side of the minichannel by an SP-5000M-CXP2 fast camera (manufactured by $J A I$ ). K-type thermocouples and pressure meters were placed at the inlet and outlet of the minichannel. The power supply and control system consists of: an inverter welder, a shunt, an ammeter and a voltmeter. The lighting system comprises high power LEDs $(400 \mathrm{~W})$ to provide light for the two-phase flow structures.

During experiments, after the desired values of the pressure and flow rate were reached, the electric power supplied to the heated plate was increased gradually to achieve an increase in the heat flux transferred to the fluid. It caused a change in the heat transfer between the plate and the fluid from single phase convection to nucleate boiling during refrigerant flow along the minichannel.

\section{Calculations of the local heat transfer coefficient}

The authors of $[11,15-18]$ presented various methods of determining the local heat transfer coefficient in the twodimensional approaches employing Trefftz or Beck methods obtained from solving the inverse problem. Trefftz functions are used for various heat transfer calculations [30-33].

In this paper, one-dimensional approach is used for calculations, taking into account the heat flow direction, which is perpendicular to the direction of the fluid flow in the minichannel. Local heat transfer coefficients in the subcooled boiling region are determined from the following equation:

$$
\alpha(x)=\frac{\frac{I \cdot \Delta U}{A}-q_{w, l o s s}}{T p(x, \delta)-T_{f}(x)-\left(\frac{I \cdot \Delta U}{A}-q_{w, l o s s}\right) \cdot \frac{\delta p}{\lambda_{p}}}
$$

where $x$-distance from the minichannel inlet along the direction of the flow, $T_{P}-$ the plate temperature measured by infrared thermography, $T_{f}-$ fluid temperature determined on the basis of the linear distribution of fluid temperature along the length of the minichannel from the inlet to the outlet, $\lambda_{P}-$ the coefficient of thermal conductivity of the plate, $\delta_{P}-$ the plate thickness, $I-$ current, $\Delta U-$ voltage drop, $A$ - surface area of the heated plate, $q_{w, l o s s}-$ heat loss to the surroundings [13].

\section{Results}

All measurements were recorded for the assumed heat flux supplied to the minichannel's heated plate, in stable similar thermal and flow conditions, thus the experimental results relate to the steady state. Data from experiments conducted using vertical orientation of the test section with a minichannel (position $90^{\circ}$ - upward flow and position $270^{\circ}$ - downward flow, see Fig. 1b) and two different mass flow velocities $\left(Q_{m}=6 \cdot 10^{-3} \mathrm{~kg} / \mathrm{s}\right.$ and $Q_{m}=12 \cdot 10^{-3} \mathrm{~kg} / \mathrm{s}$ ), at the subcooled boiling region, were analyzed. The results are presented as relationships between the heated plate temperature and the distance from the minichannel inlet (Fig. 3), the heat transfer coefficient and the distance from the minichannel inlet (Fig. 4), boiling curves (Fig. 5a), the heat flux vs. the heat transfer coefficient (Fig. 5b) and images of twophase flow structures (Fig. 6).

Analysis of temperature distributions on the heated surface, shown in Fig. 3, indicated certain similarities and differences depending on upward and downward flows and mass flow velocities. The highest plate temperatures were achieved at position $270^{\circ}$ and lower mass flow velocity $\left(Q_{m}=6 \cdot 10^{-3} \mathrm{~kg} / \mathrm{s}\right)$ for the highest heat flux $\left(48 \mathrm{~kW} / \mathrm{m}^{2}\right)$, Fig. 3c. For lower heat fluxes (23 and $\left.35 \mathrm{~kW} / \mathrm{m}^{2}\right)$, the highest temperature distributions was obtained at position $90^{\circ}$ and at the same mass flow velocity (Fig. 3). The lowest plate temperatures were observed at position $270^{\circ}$ and higher mass flow velocity $\left(Q_{m}=12 \cdot 10^{-3} \mathrm{~kg} / \mathrm{s}\right)$ for all heat fluxes. Moreover, at position $270^{\circ}$ and lower mass flow velocity locally low plate temperatures were also noticed, see Fig. 3.

The highest values of the local heat transfer coefficients were achieved at position $270^{\circ}$ and lower mass flow velocity and $35 \mathrm{~kW} / \mathrm{m}^{2}$ heat flux, Fig. $4 \mathrm{~b}$. For other heat fluxes, the higher heat transfer coefficient values were obtained at position $270^{\circ}$ and higher mass flow velocity, Figs. 4a,c. The lowest heat transfer coefficient were observed at position $270^{\circ}$ and lower mass flow velocity and at the highest heat flux, Fig. 4c. Moreover, it can be observed that local heat transfer coefficients at position $90^{\circ}$ and all mass flow velocities reached similar values in the central part of the minichannel.

Boiling curves shown in Fig. 5a were constructed for upward and downward flows along the minichannel and two mass flow velocities. These curves were plotted as the heat flux against the difference $T_{P^{-}} T_{f}$ at $0.135 \mathrm{~m}$ distance from the minichannel inlet. The boiling curves are similar, except one obtained at position $270^{\circ}$ and lower mass flow velocity with visible temperature difference drop accompanying the onset of boiling. The plots of the other boiling curves do not exhibit such a temperature drop. The relationships between the heat flux and the heat transfer coefficient in Fig. 5b confirm the findings from the analysis of the previous figures. The highest difference between the curve plots is observed at the position $270^{\circ}$ and lower mass flow velocity. 


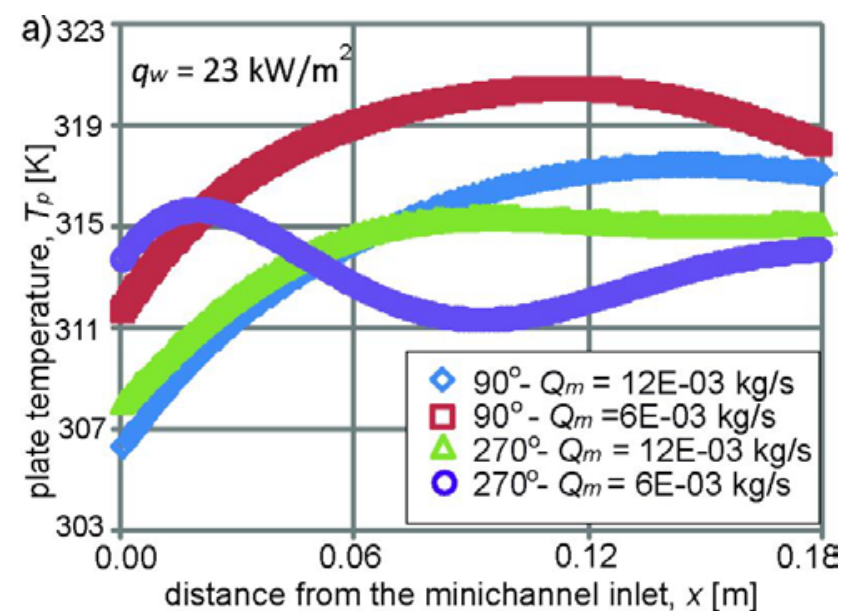

b)

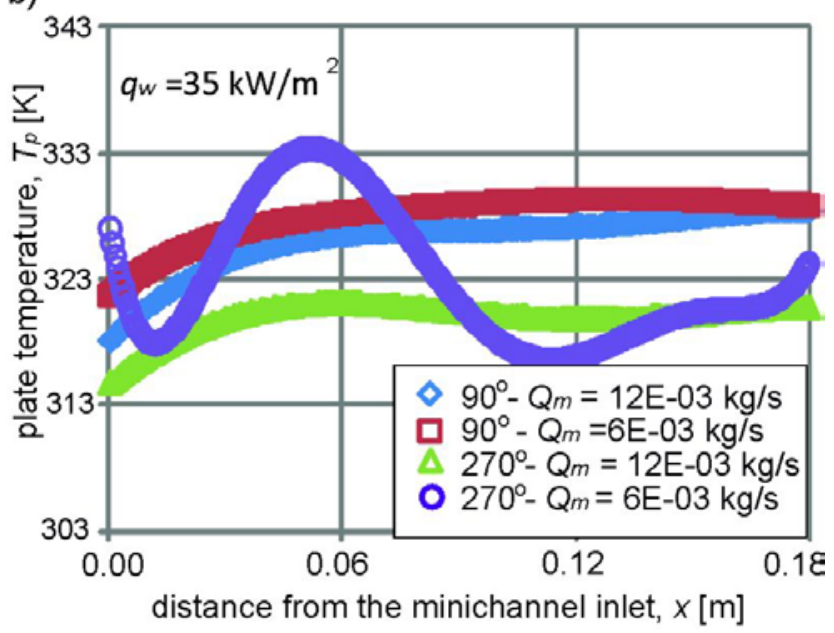

C)

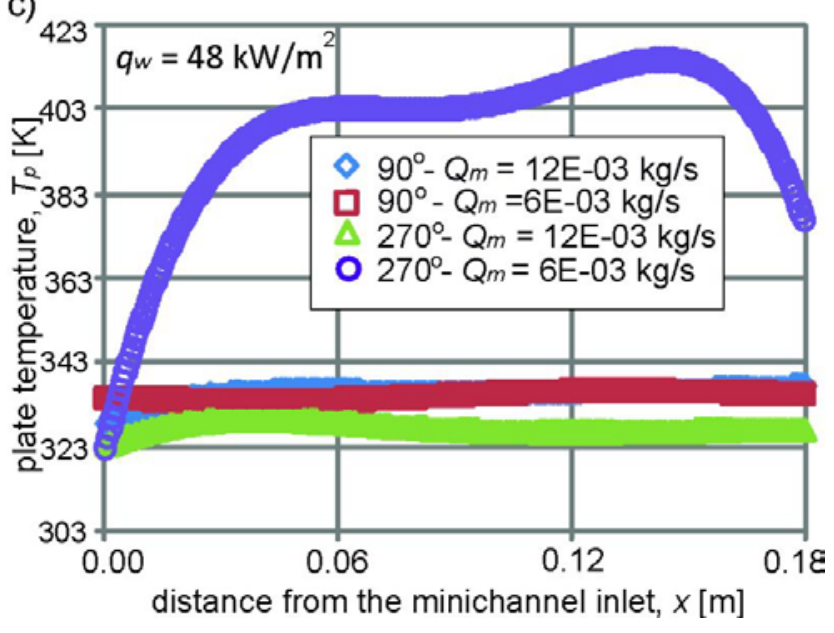

Fig. 3. The plate temperature vs. the channel length, for upward and downward flows along the minichannel and two selected mass flow velocities, at the subcooled boiling region.
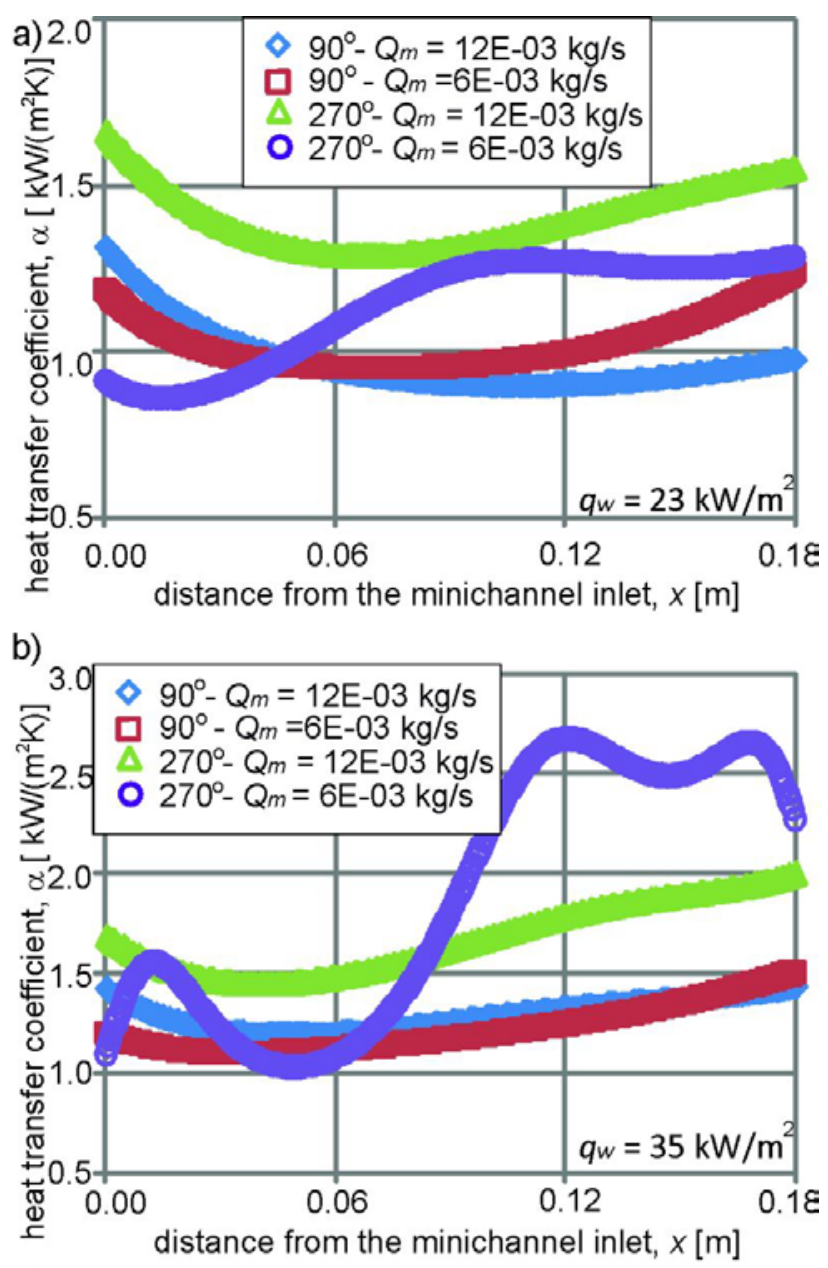

c)

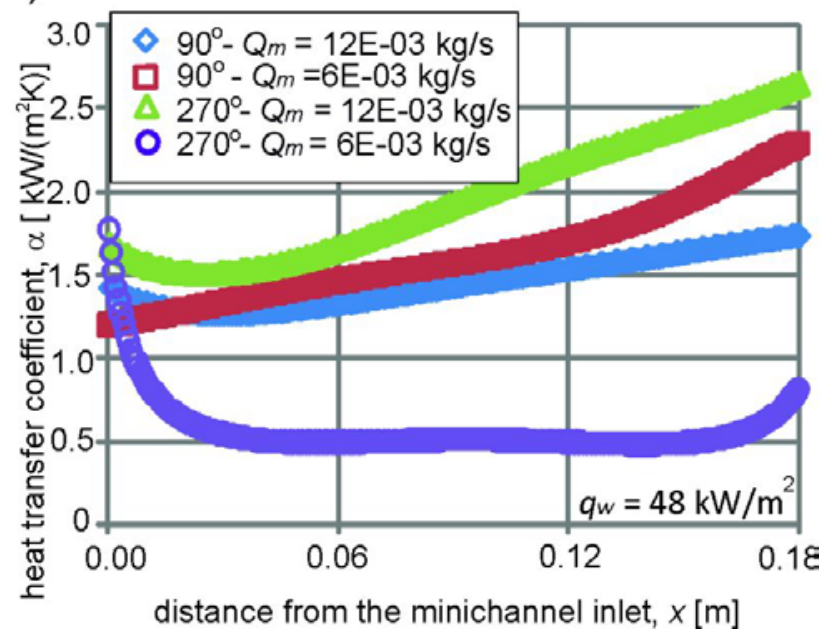

Fig. 4. The heat transfer coefficient vs. the channel length, for upward and downward flows along the minichannel and two selected mass flow velocities, at the subcooled boiling region. 

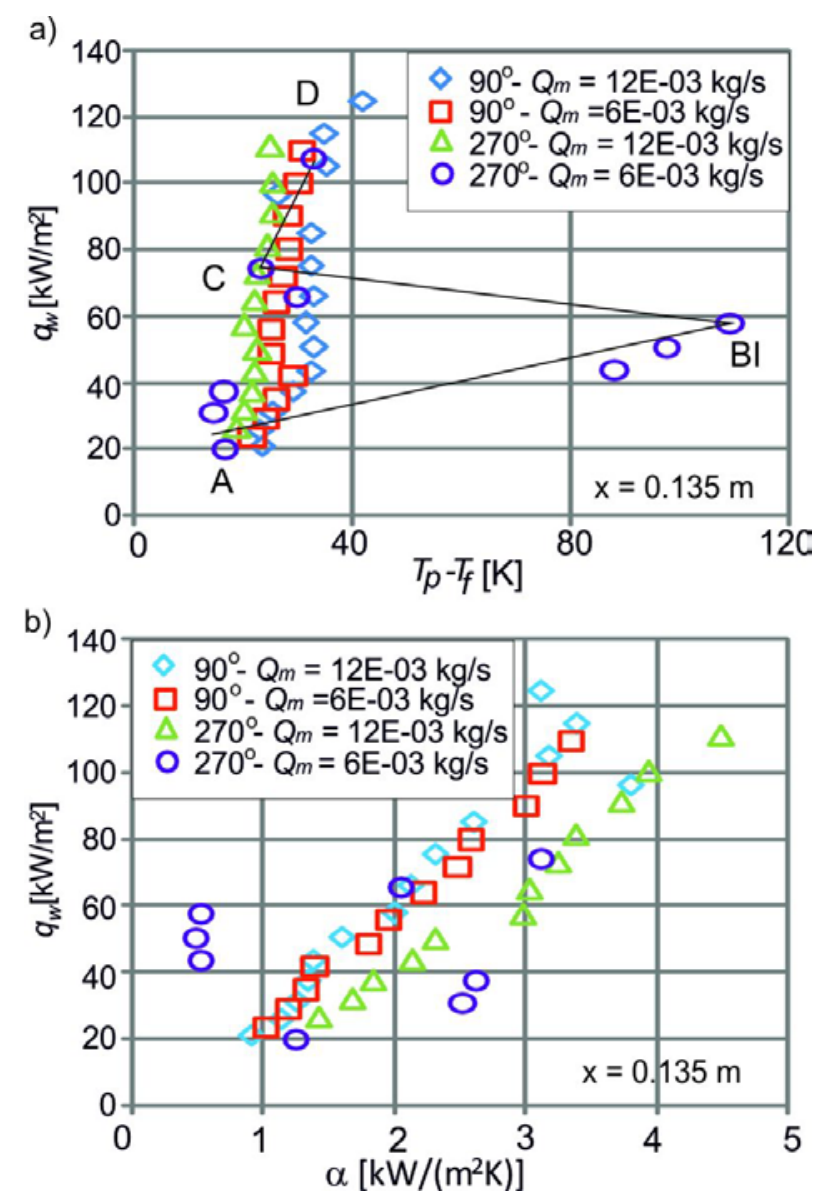

Fig. 5. a) Boiling curves, b) the heat flux vs. the heat transfer coefficient, constructed for $0.135 \mathrm{~m}$ distance from the minichannel inlet, BI - boiling incipience.

Images of selected HFE-649 two-phase structures, recorded for selected measurement series in the minichannel for the entire boiling region are shown in Fig. 6. In vertical upflow (position $90^{\circ}$ ), Figs. 6a-b, only tiny, single vapour bubbles were observed along the whole length of the minichannel and more bubbles were observed near outlet (Fig. 6a, A). With the aid of the dominant buoyancy force, the bubbles moved upward in the direction of the outlet (where the fluid was most heated). Compared to position $90^{\circ}$, more gaseous phase was observed during boiling at the position $270^{\circ}$ (Figs. 6c-d). In vertical downflow (position $270^{\circ}$ ) relative to gravity (dominant with respect to the buoyancy force). The developed annular structures formed at the lowest heat flux at the inlet of the minichannel (Figs. 6c-d, I). The increasing heat flux "pushed" the annular structure upwards, thereby forming vapour locks along the minichannel length (Figs. 6c-d, II). At lower mass flow velocity at the position $270^{\circ}$ (Fig. 6c, B), the annular structures forming in the inlet are larger compared with the case of the same channel position and higher mass flow velocity (Fig. 6d, C).
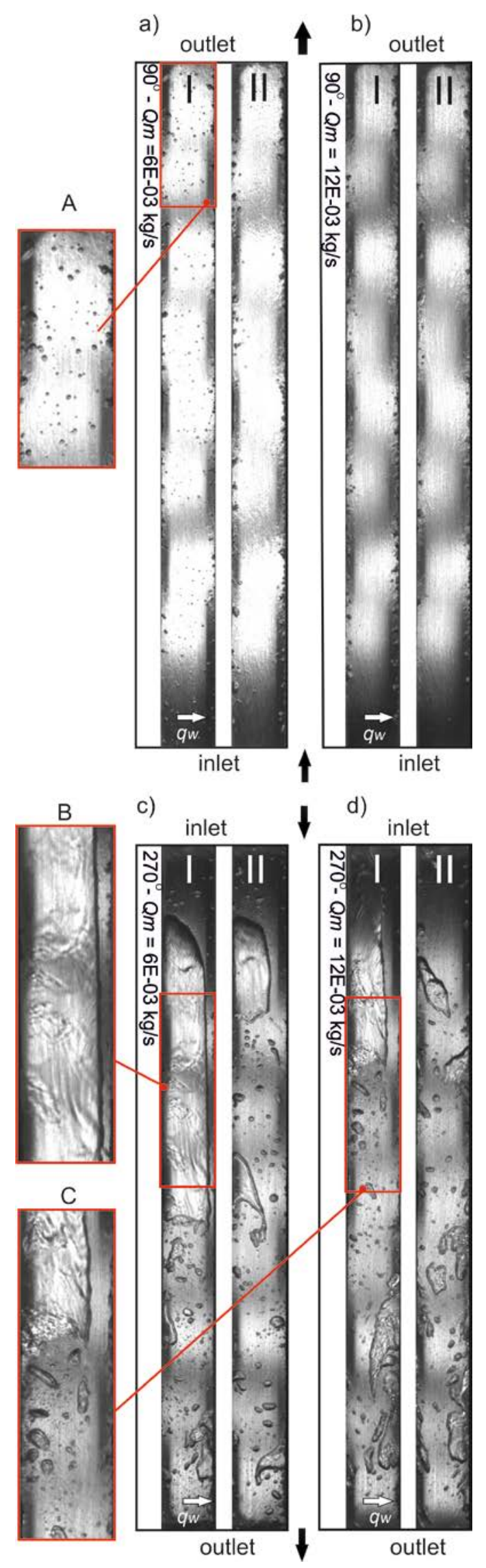

Fig. 6. Images of two-phase flow structures for upward and downward flows: position $90^{\circ}(\mathrm{a}, \mathrm{b})$ and position $270^{\circ}(\mathrm{c}, \mathrm{d})$, at mass flow velocities: $Q_{m}=6 \cdot 10^{-3} \mathrm{~kg} / \mathrm{s}(\mathrm{a}, \mathrm{c})$ and $Q_{m}=12 \cdot 10^{-3}$ $\mathrm{kg} / \mathrm{s}(\mathrm{b}, \mathrm{d})$. 


\section{Conclusions}

This paper presents the results of HFE-649 flow boiling heat transfer in a rectangular minichannel verticallyoriented for upward and downward flows and two mass flow velocities $\left(6 \cdot 10^{-3} \mathrm{~kg} / \mathrm{s}\right.$ and $\left.12 \cdot 10^{-3} \mathrm{~kg} / \mathrm{s}\right)$. Infrared thermography allowed to determine changes in the temperature on the outer side of the channel. The twophase flow structures were recorded through a glass pane at the other side of the minichannel being in contact with the fluid. The results are shown as relationships between: the heat transfer coefficient or the plate temperature and the distance along the minichannel length, boiling curves, the heat flux versus the heat transfer coefficient, and in the form of two-phase flow structure images.

The analysis indicated that the highest plate temperature were obtained for the downflow case at lower mass flow velocity and for at the highest heat flux. The highest values of the local heat transfer coefficients were achieved under downflow conditions and lower mass flow velocity and the average heat flux. For other heat fluxes, the higher heat transfer coefficient values were obtained at the downflow orientation and higher mass flow velocity. The lowest heat transfer coefficient were observed under downflow conditions and lower mass flow velocity and at the highest heat flux.

The constructed boiling curves were similar, except one obtained for downward flow and lower mass flow velocity, with visible temperature difference drop accompanying the onset of boiling. In vertical upflow, only tiny, single vapour bubbles were observed along the whole length of the minichannel. With the aid of the dominant buoyancy force, the bubbles moved upward in the direction of the outlet (where the fluid was most heated). At the downward flow relative to gravity, the two-phase flow structures generated during boiling behaved differently - more bubbles were observed at the inlet and the developed annular structures formed at the lowest heat flux (dominant gravity with respect to the buoyancy force).

The research reported here in was supported partially by a grant from the National Science Centre, Poland (No. DEC-2016/23/N/ST8/01247).

\section{References}

1. M. Piasecka, Heat Transf. Eng. 35 (10), 903-912 (2014)

2. T. Bohdal, H. Charun, M. Sikora, Int. J. Refrig. 59, 210-223 (2015)

3. T. Bohdal, W. Kuczynski, Heat Transf. Eng. 32(5), 359-368 (2011)

4. T. Bohdal, K. Dutkowski, Annu. Set Environ. Prot. 13, 409-423 (2011) (in Polish)

5. D. Mikielewicz, J. Wajs, R. Andrzejczyk, et al. Int. J. Refrig. 68, 226-241 (2016)

6. D. Mikielewicz, M. Klugmann, J. Wajs, Int. J. Therm. Sci. 65, 79-91 (2013)

7. R. Kaniowski, M.E. Poniewski, Arch. Thermodyn. 34(2), 3-22 (2013)
8. C.R. Kharangate, C. Konishi, I. Mudawar, Int. J. Heat Mass Transf. 92, 467-482 (2016)

9. C. Konishi, I. Mudawar, M.M. Hasan, Int. J. Heat Mass Transf. 65, 203-218 (2013)

10. J.S. Brower, J.F. Klausner, Proc. of HT-FED2004 Westin Charlotte \& Convection Center Charlotte, Charlotte, North Carolina, USA, 1-6 (2004)

11. M. Piasecka, B. Maciejewska, Exp. Therm. Fluid Sci. 68, 459-467 (2015)

12. K. Strąk, M. Piasecka, B. Maciejewska, Int. J. Heat Mass Transf. 117, 375-387(2018)

13. M. Piasecka K. Strąk, B. Maciejewska, Heat Transf. Eng. 38(3), 332-346 (2017)

14. B. Maciejewska, K. Strąk, M. Piasecka, Procedia Eng. 157, 82-88 (2016)

15. B. Maciejewska, M. Piasecka, Int. J. Heat Mass Transf. 107, 925-933 (2017)

16. B. Maciejewska, M. Piasecka, Heat Mass Transf. 53(4), 1211-1224 (2017)

17. S. Hozejowska, M. Piasecka, Heat Mass Transf. 50(3), 1053-1063 (2014)

18. B. Maciejewska, K. Strąk, M. Piasecka, Int. J. Numer. Methods Heat Fluid Flow 28(1), 206-219 (2018)

19. M. Piasecka, K. Strąk, Heat Transf. Eng., 40 (13-14) (2019)

20. M. Piasecka, K. Strak, B. Grabas, Arch. Metall. Mater. 62 (4), 1983-1990 (2017)

21. K. Strąk, M. Piasecka, EPJ Web Conf. 143, 02116 (2017)

22. K. Strąk, M. Piasecka, EPJ Web Conf. 180, 02098 (2018)

23. R. Pastuszko, EPJ Web Conf. 45, 01020 (2013)

24. R. Pastuszko, R. Kaniowski, EPJ Web Conf. 25, 02019 (2012)

25. L. J Orman, J Enhanc Heat Transf. 23(2), 137-153 (2016)

26. L. Dąbek, A. Kapjor, L. J. Orman, MATEC Web Conf. 168, 07001 (2018)

27. www.haynesintl.com/pdf/h3009.pdf

28. P. Młynarczyk, S. Spadło, W. Depczyński, et al., Proc. Met. 2015 24th Int. Conf. Metall. Mater.,792797 (2015)

29. W. Depczynski, Proc. Met. 2016 25th Int. Conf. Metall. Mater., 682-687 (2016)

30. K. Grysa, A. Maciag, Int. J. Heat Mass Transf. 100, 627-633 (2016)

31. A. Maciag, J. Theor App Mech, 49(1), 97-116 (2011)

32. M. J. Cialkowski, A. Frackowiak, K. Grysa, Int. J. Heat Mass Transf. 50 (11-12), 2170-2181 (2007)

33. S. Blasiak, A. Pawinska, Int. J. Heat Mass Transf. 90, 710-718 (2015) 